\title{
Article
}

\section{Transient Hyperthyrotropinemia in Outpatient Children with Acute Infections of the Respiratory System}

\author{
Katarzyna Adamczewska ${ }^{1}$, Zbigniew Adamczewski ${ }^{2,3}{ }^{\circledR}$, Magdalena Stasiak ${ }^{3}{ }^{\oplus}$, Andrzej Lewiński ${ }^{3,4}$ \\ and Renata Stawerska $3,5, *$ (D) \\ 1 Primary Care Unit "Medyk"-Outpatient Clinic, 95-035 Ozorków, Poland; kadamczewska@o2.pl \\ 2 Department of Nuclear Medicine, Medical University of Lodz, 92-216 Lodz, Poland; \\ zbigniew.adamczewski@umed.lodz.pl \\ 3 Department of Endocrinology and Metabolic Diseases, Polish Mother's Memorial Hospital-Research Institute, \\ 93-338 Lodz, Poland; mstasiak33@gmail.com (M.S.); andrzej.lewinski@umed.lodz.pl (A.L.) \\ 4 Department of Endocrinology and Metabolic Diseases, Medical University of Lodz, 93-338 Lodz, Poland \\ 5 Department of Pediatric Endocrinology, Medical University of Lodz, 93-338 Lodz, Poland \\ * Correspondence: renata.stawerska@umed.lodz.pl; Tel.: +48-42-2711141
}

check for

updates

Citation: Adamczewska, K.;

Adamczewski, Z.; Stasiak, M.;

Lewiński, A.; Stawerska, R. Transient

Hyperthyrotropinemia in Outpatient

Children with Acute Infections of the

Respiratory System. Int. J. Environ.

Res. Public Health 2021, 18, 4115.

https://doi.org/10.3390/

ijerph18084115

Academic Editor: Paul B. Tchounwou

Received: 28 February 2021

Accepted: 9 April 2021

Published: 13 April 2021

Publisher's Note: MDPI stays neutral with regard to jurisdictional claims in published maps and institutional affiliations.

Copyright: (c) 2021 by the authors. Licensee MDPI, Basel, Switzerland. This article is an open access article distributed under the terms and conditions of the Creative Commons Attribution (CC BY) license (https:/ / creativecommons.org/licenses/by/ $4.0 /$ )

\begin{abstract}
Background: Diagnostics of thyroid disorders (TD) are frequently based on the measurements of thyroid stimulating hormone (TSH) concentration only. If TSH is outside the reference range, the diagnostic procedure used in patients with TD isintroduced. Observations indicate that in a considerable number of these patients, TD is not confirmed. The aim of the study was to assess the incidence of transient hyperthyrotropinemia in healthy children during acute infections of the respiratory system. Patients and Methods: The study included consecutive children (49 boys and 45 girls), aged 2.2-17.3 years, who visited one General Practitioner (GP) due to respiratory tract infections. The tests: complete blood count (CBC), C-reactive protein (CRP), TSH and FT4 were run on the next day after the visit at the physician's (initial visit) and $\geq 2$ weeks after recovery. Results: Among these children, elevated TSH values were found in about $10 \%$ of patients, and they went back to normal values after recovery. A prospective analysis showed a reduction of TSH values in approx. $65 \%$ of all groups and TSH at the follow-up visit was significantly lower. Conclusions: Transient hyperthyrotropinemia was observed in about $10 \%$ of children with acute respiratory tract infection. This preliminary finding remains unexplained.
\end{abstract}

Keywords: thyroid stimulating hormone; transient hyperthyrotropinemia; acute respiratory tract infection; children

\section{Introduction}

Normal thyroid hormone (thyroxine-T4 and triiodothyronine-T3) secretion and action are essential for both fetal and post-natal neurodevelopment. It is also important for, normal growth and metabolic processes in children [1,2]. The prevalence of thyroid disease in Polish children is not very well known, but in the first two decades after mandatory salt iodination, we observed a lower incidence of goiter and a higher frequency of Graves' disease [3,4]. In the iodine-sufficient regions, the most common cause of acquired primary hypothyroidism (characterized by low free T4 (FT4) and elevated thyroid stimulating hormone (TSH) serum concentrations) is autoimmune hypothyroidism (Hashimoto's thyroiditis); its prevalence in childhood has been estimated as 1-2\% [1].

In turn, in approximately $2 \%$ of children, subclinical hypothyroidism is present. It can be defined as primary biochemically compensated hypothyroidism [1,2]. In these conditions, normal FT4 and free T3 (FT3) and elevated TSH serum concentrations are observed. The treatment of subclinical hypothyroidism is controversial, as it is usually an asymptomatic, benign condition with rare progression to over hypothyroidism. According to the current recommendations, only symptomatic children, children younger than 3 
years old, or those with TSH levels higher than $10 \mathrm{mIU} / \mathrm{L}$ require the L-T4 treatment [5-7]. The etiology of subclinical hypothyroidism is usually idiopathic-especially in the cases of transient hyperthyrotropinemia, but it also may be the initial manifestation of Hashimoto's thyroiditis $[5,6,8]$.

About $50 \%$ of patients with childhood autoimmune hypothyroidism have a family history of such diseases [1]. It is well known that the occurrence of autoimmune thyroid disease (AITD) depends onan interaction between genetic susceptibility and environmental factors. Thus, there is an ongoing debate in scientific associations and the general public about the factors that can initiate hypothyroidism. As a result, parents or legal guardians often ask General Practitioners (GPs) to screen their children for thyroid diseases.

Diagnostics of thyroid dysfunctions arefrequently based on the measurements of TSH serum concentration only. This is due to the fact that alog-linear relationship between TSH and FT4 and FT3 concentration is observed, thus abnormal TSH concentration suggests the possible occurrence of thyroid disorders [9,10]. In children, the level of TSH appears to be a stable and solid diagnostic parameter, however, its variability in laboratory tests has been observed [11]. On the other hand, there are some conditions in which the transitionally elevated TSH concentration is observed, with obesity being one of the welldocumented examples [12]. Studies concerning the influence of other transient conditions (e.g., inflammations) on TSH secretion are divergent [13,14]. However, it was proven that the elevation of several proinflammatory cytokines may affect thyroid function tests, which mimic thyroid disorders in the absence of actual thyroid disease [15,16]. The bestknown example of changes in the thyroid axis function, occurring also in children, is a non-thyroidal illness syndrome (NTIS) in critically ill patients. This phenomenon can resemble a response of healthy subjects to fasting [17]. Thyroid hormone inactivation with low T3 and high rT3 followed by suppressed TSH is the most frequently observed phenomenon in these patients. However, NTIS may also lead to elevated TSH. It was demonstrated that during the recovery phase from such diseases serum TSH level may be increased, but generally not higher than $10 \mathrm{mIU} / \mathrm{L}$ [8]. The slightly elevated TSH levels after acute infections were observed in adults [18]. The influence of NTIS on TSH concentration in children is well documented. In turn, TSH changes during the most common infections of the respiratory tract in children are observed in practice, however, data on their incidence and causes are scarce. This phenomenon was found because of the tendency to combine TSH tests with diagnostic tests made due to other reasons (e.g., infection), in order to minimize stressful situations for a child. If TSH serum concentration is outside the reference range, the diagnostic procedure used in patients with thyroid disorders isintroduced. Clinical observations indicate that in a considerable number of these patients, thyroid disease is not confirmed, and the results of the initial tests are-in fact-falsely positive.

Thus, the aim of the study was to assess the incidence of transient hyperthyrotropinemia in generally well children during acute infections of the respiratory system.

\section{Patients and Methods}

The research was approved by the Bioethical Committee at the Polish Mother's Memorial Hospital Research Institute (PMMH-RI) in Lodz (approval code 69/2018).

The study included consecutive children who visited one GP (K.A.) in a single Primary Healthcare Centre due to mild or moderate respiratory tract infections over the period of one year. In every case, medical history, as well as signs and symptoms of the infection were recorded. Each child was physically examined, i.e., the throat and tonsils were assessed by inspection, the lungs were auscultated using a stethoscope and body temperature was checked using a non-contact thermometer. No chest X-rays were performed. Next, in every case, a complete blood count $(\mathrm{CBC})$ test with differential was performed and C-reactive protein (CRP) in serum was measured. The tests were run on the next day after the visit at the physician's (peripheral blood samples were collected between 8.00 and 10.00 a.m., after overnight fasting). Venous blood was obtained by venipuncture (needle gauge 19). At the 
same time, an additional blood sample was collected to assess TSH and FT4 concentrations. Moreover, during the visit, on the basis of the height and body mass measurements, the child's nutritional status was evaluated, by assessment of the body mass index (BMI) value. Obese (BMI $>+2.0 \mathrm{SD} ; \mathrm{n}=7$ ) and undernourished $(\mathrm{BMI}<-2.0 \mathrm{SD} ; \mathrm{n}=2)$ children were excluded from the study, similarly to patients treated for thyroid diseases $(n=2)$. At the time of data collection, none of the children displayed typical signs and symptoms of thyroid disorders, e.g., goiter.

On the basis of the medical history, physical examination and the results of laboratory tests, the type of infection was diagnosed, based on the ICD-10 classification. The children were qualified into one of the following diagnostic groups: A88.0-enteroviral exanthematous fever (Boston exanthem), H66.0-suppurative otitis media, J00-acute nasopharyngitis (common cold), J02-streptococcal pharyngitis, J03-acute tonsilitis, J04-acute laryngitis, J06-acute nasopharyngitis, J18-pneumonia (unspecified), J20-acute bronchitis, J36-peritonsillar abscess.

It was noted whether the infection was accompanied by a fever over $38{ }^{\circ} \mathrm{C}$ and elevated lab inflammatory markers (Table 1 ).

Table 1. The clinical characteristics of the analyzed group of patients.

\begin{tabular}{|c|c|c|c|c|c|c|c|c|}
\hline ICD-10 & & No. & $\begin{array}{c}\text { Fever } \\
>38^{\circ} \mathrm{C}\end{array}$ & $\begin{array}{l}\text { Elevated } \\
\text { CRP }\end{array}$ & $\begin{array}{l}\text { Elevated } \\
\text { WBC }\end{array}$ & Neutrophilia & Lymphocytosis & $\begin{array}{c}\text { Elevated } \\
\text { TSH }\end{array}$ \\
\hline A88.0 & $\begin{array}{l}\text { Enteroviral } \\
\text { exanthematous fever } \\
\text { (Boston exanthema) }\end{array}$ & 1 & 1 & 0 & 1 & 0 & 0 & 0 \\
\hline H66.0 & Suppurative otitis media & 2 & 2 & 2 & 1 & 2 & 2 & 2 \\
\hline J00 & $\begin{array}{l}\text { Acute nasopharyngitis } \\
\text { (cold) }\end{array}$ & 7 & 1 & 0 & 1 & 1 & 1 & 1 \\
\hline J02 & $\begin{array}{l}\text { Streptococcal } \\
\text { pharyngitis }\end{array}$ & 25 & 19 & 10 & 7 & 7 & 7 & 3 \\
\hline J03 & Acute tonsilitis & 2 & 2 & 0 & 0 & 0 & 0 & 0 \\
\hline J04 & Acute laryngitis & 11 & 0 & 3 & 2 & 4 & 4 & 1 \\
\hline J06 & Acute nasopharyngitis & 19 & 5 & 4 & 1 & 5 & 7 & 1 \\
\hline J18 & $\begin{array}{l}\text { Pneumonia } \\
\text { (unspecified) }\end{array}$ & 5 & 2 & 3 & 1 & 2 & 1 & 0 \\
\hline $\mathrm{J} 20$ & Acute bronchitis & 21 & 9 & 7 & 5 & 6 & 2 & 1 \\
\hline J36 & Peritonsillar abscess & 1 & 1 & 1 & 1 & 1 & 0 & 0 \\
\hline Total & & $\begin{array}{c}94 \\
(100 \%)\end{array}$ & $\begin{array}{c}48 \\
(51.1 \%)\end{array}$ & $\begin{array}{c}30 \\
(31.9 \%)\end{array}$ & $\begin{array}{c}20 \\
(23.4 \%)\end{array}$ & $\begin{array}{c}28 \\
(29.8 \%)\end{array}$ & $\begin{array}{c}18 \\
(19.1 \%)\end{array}$ & $\begin{array}{c}9 \\
(9.6 \%)\end{array}$ \\
\hline
\end{tabular}

Next, the parents were asked to bring the child for a check-up examination after $\geq 2$ weeks after recovery. At the follow-up visit, the patient's condition was evaluated again and a blood sample was taken between 8.00 and $10.00 \mathrm{a} . \mathrm{m}$. in order to assess the same parameters: CBC, CRP, TSH and FT4. Thus, the blood samples were collected from the same patient at two consecutive time points: an initial visit during infection and a follow-up visit (which took place 2 weeks to 6 months after recovery). In each case where TSH was elevated the first time, the concentrations of thyroid peroxidase antibodies (a-TPO) and thyroglobulin antibodies (a-Tg) were assessed in the second blood sample.

Finally, 94 children ( 49 boys and 45 girls), aged $2.2-17.3$ years, mean \pm SD: $8.22 \pm 3.98$ years) were included in the study group. Among them, 76 children were qualified for the younger group: boys $<12$ years old and girls $<11$ years old, and 18 children for the older group: boys $\geq 12$ years old and girls $\geq 11$ years old.

The following parameters were considered significant inflammatory markers: 
1. high CRP_according to World Health Organization recommendation-over $10 \mathrm{mg} / \mathrm{L}$ [19];

2. high white blood cell (WBC) count-above the reference range quoted on the test result, i.e., over 17.500 leukocytes $/ \mathrm{mm}^{3}$ for children up to 5 years old, over 15.000 leukocytes $/ \mathrm{mm}^{3}$ for children aged 6-12 years, and over 11.000 leukocytes $/ \mathrm{mm}^{3}$ for children over 12 years;

3. increase in the proportion of lymphocytes (lymphocytosis)-above the reference range quoted on the test result, i.e., over $60 \%$ for children up to 5 years old, over $48 \%$ for children aged $6-12$ years, and over $45 \%$ for children over 12 years;

4. increase in the proportion of neutrophils (neutrophilia)-above the reference range quoted on the test result, i.e., $51 \%$ for children up to 5 years old, over $59 \%$ for children aged $6-12$ years, and over $55 \%$ for children over 12 years.

Concentrations of TSH and FT4 were measured by the electrochemiluminescent immunoassays (ECLIA) method with commercially available appropriate kits (Roche Diagnostic, Mannheim, Germany). Normal range values were as follows: for TSH: age-dependent ranges- $1-7$ years- $0.7-5.97 \mathrm{mIU} / \mathrm{L} ; 7-12$ years- $0.6-4.84 \mathrm{mIU} / \mathrm{L} ; 12-18$ years0.51-4.4 mIU/L with inter-assay coefficients of variation (CVs) $1.3-1.8 \%$ and for FT4: age-dependent ranges- $1-6$ years- $0.96-1.77 \mathrm{ng} / \mathrm{dL} ; 6-11$ years- $0.97-1.67 \mathrm{ng} / \mathrm{dL} ; 11-18$ years$0.98-1.63 \mathrm{ng} / \mathrm{dL}$ with CVs 2.0-2.4\%. All assays were performed as a part of a standardpatient care in the same laboratory cooperating with the GP clinic. The range of WBC, TSH and FT4 reference values were established on the basis of data from this laboratory.

The data were analyzed using Statistica 11.0 PL software (StatSoft, Inc., Tulsa, OK, USA). The continuous variables were expressed as mean \pm SD for normally distributed variables. Shapiro-Wilk test was used to test the distribution of the variables. The differences between girls and boys were compared using $\mathrm{chi}^{2}$ test. Correlations were evaluated using the Pearson's test. A one-way ANOVA was applied for statistical analysis with the subsequent use of a post-hoc test, in order to statistically assess differences between groups; Tukey's test was selected because of the uneven amount of data in individual groups. To compare the frequency of cases with elevated TSH between the younger and the older group of children, Fisher's exact test was used. $p<0.05$ was accepted as statistically significant value.

\section{Results}

In the study group of the 94 children, 68 (72.3\%) were diagnosed with an infection of the upper respiratory tract, while $26(27.7 \%)$-with an infection of the lower respiratory tract. The infection was accompanied by fever in over half $(51.1 \%)$ of the examined children. Elevated CRP was observed in $31.9 \%$, neutrophilia or elevated WBC were found in $23.4 \%$ and $29.8 \%$, respectively while lymphocytosis-in $19.1 \%$ of the patients. Table 1 presents the results of the analyzed study group depending on the clinical diagnosis.

In nine children from the studied group (9.6\%), TSH concentration values exceeded the upper limit of the normal range, but none of them exceeded $7.0 \mathrm{mIU} / \mathrm{L}$. In the check-up examination performed after recovery, elevated TSH values were not observed in any of the children (Figure 1). A detailed analysis of the cases in whichelevated TSH was found is presented in Table 2. Among children with elevated TSH found at the first time point (during infection), five patients had fever. In this subgroup (cases with elevated TSH concentration and fever), four children had elevated CRP, and among them, one had increased WBC and three neutrophilia, while in the fourth case, the CBC test result was normal. In the fifth child with fever, CRP and WBC were not elevated, but an increased number of neutrophils was observed. Three children did not have fever or elevation of any of the biochemical inflammatory markers. 
Table 2. A detailed analysis of the cases where elevated thyroid stimulating hormone (TSH) was found.

\begin{tabular}{|c|c|c|c|c|c|c|c|c|c|c|c|c|c|c|c|c|c|}
\hline \multirow[b]{2}{*}{ Gender } & \multirow[b]{2}{*}{$\begin{array}{c}\text { Age } \\
\text { (years) }\end{array}$} & \multirow[b]{2}{*}{$\begin{array}{l}\text { Type of } \\
\text { Infection }\end{array}$} & \multirow[b]{2}{*}{$\begin{array}{c}\text { ICD- } \\
10\end{array}$} & \multirow[b]{2}{*}{ Fever } & \multirow[b]{2}{*}{$\begin{array}{c}\mathrm{CRP} \\
\mathrm{mg} / \mathrm{L}\end{array}$} & \multicolumn{4}{|c|}{ Initial Visit } & \multirow[b]{2}{*}{$\begin{array}{c}\text { FT4 } \\
\text { ng/dL }\end{array}$} & \multirow[b]{2}{*}{$\begin{array}{c}\text { Days between } \\
\text { Initial and } \\
\text { Follow-Up Visits }\end{array}$} & \multicolumn{3}{|c|}{ Follow-Up Visit } & \multirow[b]{2}{*}{$\begin{array}{c}\text { Lym } \\
\%\end{array}$} & \multirow[b]{2}{*}{$\begin{array}{l}\text { TSH } \\
\mathrm{mIU} / \mathrm{L}\end{array}$} & \multirow[b]{2}{*}{$\begin{array}{c}\text { FT4 } \\
\text { ng/dI }\end{array}$} \\
\hline & & & & & & $\begin{array}{l}\text { WBC } \\
10^{9} / \mathrm{L}\end{array}$ & $\underset{\%}{\text { Neu }}$ & $\begin{array}{c}\text { Lym } \\
\%\end{array}$ & $\begin{array}{c}\text { TSH } \\
\mathrm{mIU} / \mathrm{L}\end{array}$ & & & $\begin{array}{l}\text { CRP } \\
\mathrm{mg} / \mathrm{L}\end{array}$ & $\begin{array}{l}\text { WBC } \\
10^{9} / \mathrm{L}\end{array}$ & $\begin{array}{c}\text { Neu } \\
\%\end{array}$ & & & \\
\hline $\mathrm{F}$ & 12 & Upper resp. tract & H66 & Yes & $19.81(\uparrow)$ & $13.9(\uparrow)$ & $74.2(\uparrow)$ & 13.9 & 4.57 & 1.33 & 30 & $<1$ & 7.5 & 42 & 44.1 & 2.56 & 1.27 \\
\hline $\mathrm{M}$ & 4 & Upper resp. tract & H66 & Yes & $68.08(\uparrow)$ & 10.1 & $52.5(\uparrow)$ & 25.7 & 6.9 & 1.25 & 28 & $<1$ & 8.06 & 37.2 & 49.8 & 4.02 & 1.19 \\
\hline $\mathrm{M}$ & 11 & Upper resp. tract & J00 & No & $<1$ & 6.83 & 42.6 & 42.9 & 5.16 & 0.98 & 35 & $<1$ & 6.44 & 50.1 & 36 & 3.04 & 1.21 \\
\hline F & 14 & Upper resp. tract & $\mathrm{J} 02$ & Yes & $10.51(\uparrow)$ & $14.67(\uparrow)$ & $69.4(\uparrow)$ & 16.9 & 5.09 & 1.31 & 21 & $<1$ & 6.85 & 43.9 & 45.0 & 4.36 & 1.23 \\
\hline $\mathrm{M}$ & 6 & Upper resp. tract & J02 & No & 3.26 & 11.33 & 32.1 & $55.5(\uparrow)$ & 6.78 & 1.27 & 46 & $<1$ & 5.77 & 56 & 33.8 & 5.77 & 1.33 \\
\hline $\mathrm{F}$ & 3 & Upper resp. tract & J04 & No & $<1$ & 8.5 & 46.7 & 36.4 & 6.64 & 1.12 & 21 & $<1$ & 7.91 & 29.2 & 58.3 & 5.56 & 1.18 \\
\hline $\mathrm{F}$ & 11 & Upper resp. tract & J06 & No & 1.04 & 9.3 & 44.9 & 43.9 & 5.95 & 1.22 & 37 & $<1$ & 9.43 & 48 & 41.1 & 4.13 & 1.20 \\
\hline $\mathrm{M}$ & 4 & Lower resp. tract & $\mathrm{J} 20$ & Yes & $33.11(\uparrow)$ & 4.21 & 35.9 & 35.9 & 5.85 & 1.44 & 15 & $<1$ & 8.73 & 51 & 30.8 & 3.15 & 1.37 \\
\hline
\end{tabular}




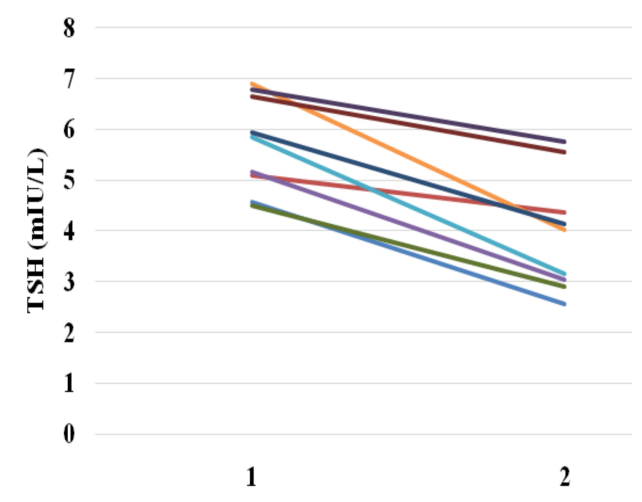

Figure 1. TSH concentration during infection (1) and during the check-up (2) in the group of children with elevated TSH concentration at the first examination (during infection).

In all of the analyzed cases, TSH concentration returned to normal in the check-up examination, performed after infection resolution. In none of the cases, FT4 concentration was reduced - the values ranged from 0.98 and $1.44 \mathrm{ng} / \mathrm{dL}$, with the mean value of $1.25 \mathrm{ng} / \mathrm{dL}$. An elevated a-TPO or a-Tg levels were not observed either.

In the whole group of the 94 examined children, TSH concentrations were analyzed with respect to the occurrence of inflammation symptoms mentioned above. Thus we compared TSH levels between the groups of children with and without fever, with normal and with elevated CRP, with normal and with elevated WBC, with normal and with an elevated count of neutrophils and with normal and with an elevated count of lymphocytes. Statistically significant differences between groups were not found, only in CRP-dependent analysis, the differences between groups were on the border of statistical significance (Table 3). A multivariance analysis confirmed that TSH level was not significantly influenced by any of the parameters in question (type of infection, fever, elevated value of CRP, WBC, elevated count of lymphocytes or neutrophils).

Table 3. The mean TSH levels $( \pm S D)$ at the initial visit in children with and without fever, with and without elevated C-reactive protein (CRP), with and without elevated white blood cells (WBCs), with and without elevated neutrophils and with and without elevated lymphocytes.

\begin{tabular}{cccc}
\hline & Normal & Elevated & $p=$ \\
\hline body temperature & $2.93 \pm 1.27$ & $2.85 \pm 1.27$ & 0.76 \\
CRP & $2.74 \pm 1.24$ & $3.23 \pm 1.27$ & 0.08 \\
WBC count & $2.79 \pm 1.18$ & $3.23 \pm 1.48$ & 0.15 \\
neutrophils count & $2.83 \pm 1.26$ & $3.04 \pm 1.27$ & 0.48 \\
lymphocytes count & $2.90 \pm 1.29$ & $2.88 \pm 1.23$ & 0.98 \\
\hline
\end{tabular}

We also compared TSH and FT4 levels between the younger (prepubertal) and older (pubertal) groups of children. We found no differences between the groups in terms of the parameters mentioned above. We found that elevated TSH was more common in older children, but the relevance of this finding is uncertain due to the unequal number of children in the two groups (Table 4). 
Table 4. Characteristics of the analyzed group of children depending on the age (the younger group: boys $<12$ years old and girls $<11$ years old) and the older group: boys $\geq 12$ years old and girls $\geq 11$ years old).

\begin{tabular}{cccc}
\hline & Younger Children $\mathbf{n}=\mathbf{7 6}$ & Older Children $\mathbf{n}=\mathbf{1 8}$ & $p=$ \\
\hline Girl/boys & $32 / 44$ & $13 / 5$ & \\
Age (years) & $6.79 \pm 2.75$ & $14.5 \pm 1.53$ & $<0.000$ \\
TSH (mIU/L) & $2.88 \pm 1.29$ & $2.95 \pm 1.16$ & NS \\
FT4 (ng/mL) & $1.24 \pm 0.08$ & $1.24 \pm 0.11$ & NS \\
Elevated TSH n (\%) & $5(6.6)$ & $4(22.2)$ & 0.06 \\
\hline
\end{tabular}

On the other hand, in the studied group of children, TSH concentration decreased in 61 out of 94 children (64.9\%) in the check-up examination (after infection) regardless of its baseline value. Moreover, a reduction of more than $10 \%$ was observed in 37 children $(39.4 \%)$. The mean values of TSH $( \pm \mathrm{SD})$ were $2.93 \pm 1.32$ and $2.67 \pm 1.05 \mathrm{mIU} / \mathrm{L}$ at the initial visit and the follow-up visit, respectively. The statistical analysis based on Wilcoxon's signed-rank test showed significant differences between TSH levels at the initial visit and the follow-up visit $(p=0.007)$.

FT4 levels were within the normal range in all of the children and there was no significant correlation between TSH and FT4 levels, $\mathrm{r}=+0.10, p>0.05$ (Figure 2). Moreover, FT4 concentration did not change between the initialand the follow-up visit.

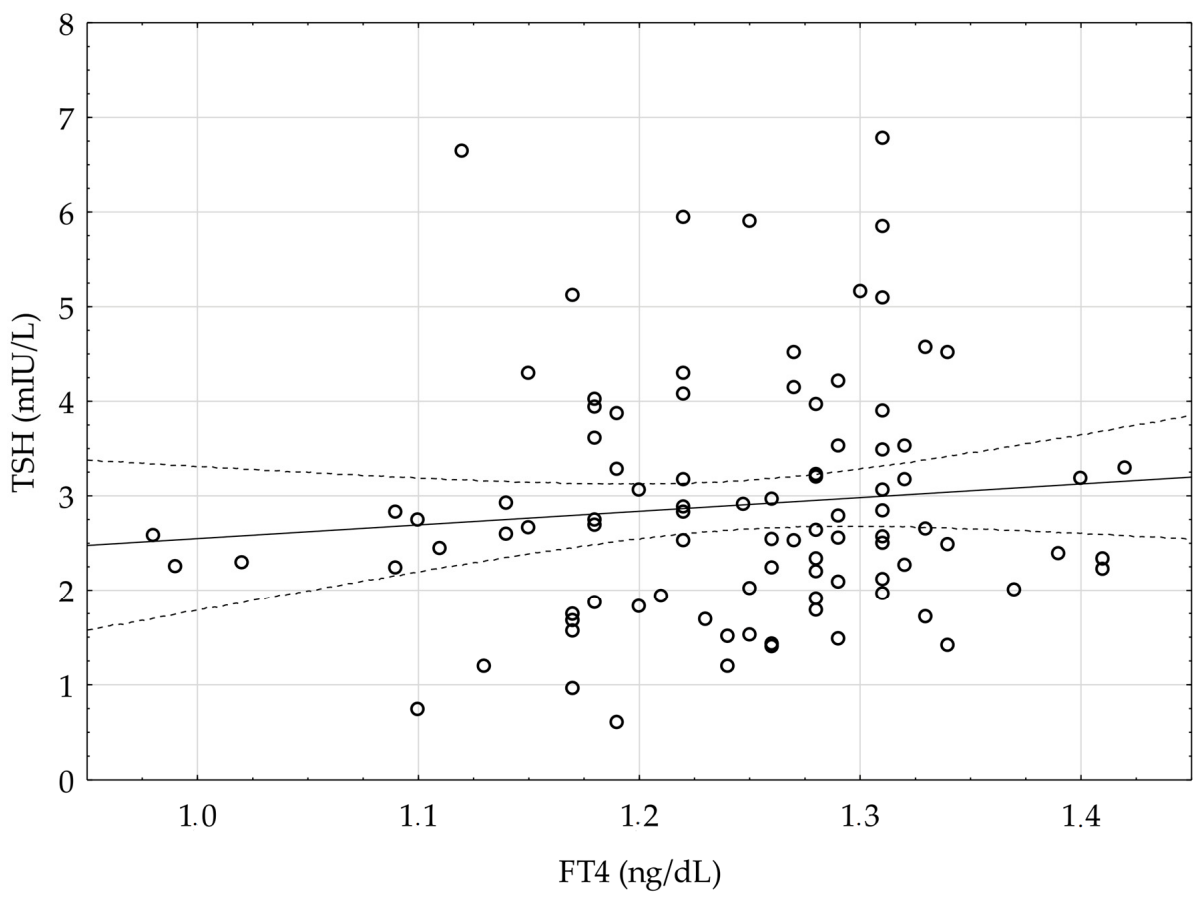

Figure 2. Correlation between TSH and FT4 concentration assessed in children during infection (Initial visit), $\mathrm{r}=+0.10, p>0.05$.

\section{Discussions}

Every disease, including infections, especially in the acute phase, disturbs the balance between anabolic and catabolic processes. Thyroid hormones play an important role in maintaining homeostasis in response to environmental challenges. Beneficial adaptation includes decreasing energy consumption and stimulation of an immunological response, which are crucial to survival [16].

The host's defense against infection involves the mechanisms of immunity and tolerance. While immunity promotes the elimination of pathogens, tolerance promotes adaptation to a given type of pathogen or to the intensity of the inflammatory response [20,21]. 
It is worth mentioning that there are two forms of adaptation activity. Type 1 allostasis occurs in diseases and conditions related to energy deficiency when the energy demand exceeds the supply and the stored energy resources. On the other hand, type 2 allostasis, occurs when the demand for energy does not exceed the potential supply, which is sufficient in relation to the needs $[22,23]$. Allostasis mediators involved in the acute phase reaction are proinflammatory cytokines. CRP is an acute-phase protein, whose synthesis in the liver is regulated by these cytokines. Its level is proportional to the concentration of inflammation mediators, which - in turn - positively correlates with the intensity of the inflammatory processes. CRP concentration exceeding $100 \mathrm{mg} / \mathrm{L}$ (often over 500 or $1000 \mathrm{mg} / \mathrm{L}$ ) is usually found in serious bacterial infections. In the course of viral infections, usually normal or slightly elevated CRP concentrations are observed [24,25]. Therefore, we assessed CRP as one of the most important parameters indicating the type of infection and the phase response in our study.

The elevation of several proinflammatory cytokines may affect thyroid function tests. The acute phase of infection is mainly characterized by intensification of anterior pituitary hormone secretion and a peripheral inactivation of anabolic hormones [13]. One of the first alterations in acute illness is inhibition of type 1 deiodinase (D1) and type 2 deiodinase (D2) in peripheral tissues and subsequent impaired conversion of T4 to T3, leading to a decrease in serum and tissue T3 levels soon after the onset of acute illness [26]. D1 also deiodinates rT3, so the degradation is impaired and the levels of this inactive hormone rise simultaneously with the fall in T3 levels. Thus, TSH concentration temporarily increases in the first hours of the critical illness, which is followed by a temporary increase of T4 in the serum. Atthe same time, T3 concentration may already be reduced and reverse triiodothyronine (rT3) concentration may be elevated due to acute changes in the peripheral metabolism of thyroid hormone [27]. The scale of changes in T3 and rT3 concentration in the blood serum depends on the severity of the disease. This results in the NTIS [16]. In patients with mild to moderate NTIS, changes in T4 and TSH concentration are usually not observed, while patients suffering longer and from a more severe illness demonstrate low concentrations of T4 and TSH, as well [14].

In our study, in all the cases, we dealt with the acute form of common infection of the respiratory tract, which occurred in previously healthy, well-being children and was successfully cured in an outpatient clinic. Thus, the changes observed in NTIS, especially $\mathrm{T} 3$ and $\mathrm{rT} 3$ concentrations, were not a subject of our research. It is difficult to explain the reasons for the transient elevation of TSH levels observed in some children among our study group and the observed tendency to a higher TSH concentration during the infection period as compared to the period after recovery. We did not identify a significant correlation between increased TSH and individual, commonly available inflammatory markers, such as CRP, lymphocytosis and the presence of fever. Infection may trigger different reactions, depending on the kind of pathogen and the progress of infection. Thus, it may be difficult to clearly classify the observed abnormalities induces by infection into any of the two forms of adaptive activity. This may imply a more complex background of the phenomenon.

Temperature-induced changes of the thyroid or thyroid axis function are well known. One of them is the physiological increase in TSH concentration in response to exposure to cold, followed by an increase in the thyroid hormone synthesis, which stimulates metabolism [28].

However, the influence of high temperatures is ambiguous. The interesting data were provided by Oka et al. In their study, the evaluation of the influence of body temperature (BT), ranging from 37.5 to $40.5{ }^{\circ} \mathrm{C}$, conducted in a group of 64 febrile patients, showed a relationship between BT and thyroid function. A negative correlation betweenTSH concentration and BT and a positive correlation between FT4 concentration and BT were observed. A detailed data analysis indicated that $8.2 \%$ of patients demonstrated an increased TSH concentration. This phenomenon was observed only for temperatures ranging from 37.5 to $38.5^{\circ} \mathrm{C}$ and was not found in patients with higher temperatures [29]. 
Moreover, the experimental studies on the impact of temperature on thyroid function demonstrated that acute hyperthermia resulted in decreased blood flow to the thyroid gland and decreased secretion of FT4 and FT3, while TSH levels were not affected [30].

We also cannot disregard the significance of the loss of appetite during acute infection. The relationship between fasting and ghrelin, whose concentration correlates positively with TSH concentration, is well known. It is highly probable because the hormonal profile observed in the study group (increased TSH concentration during infection with no impact on FT4 concentration) is characteristic for the activity of ghrelin, whose elevated concentration directly inhibits T4 synthesis [31,32].

The highly complex processes, which take place in a living organism during acute infection may influence the thyroid axis at different levels and in an equally complex way. The concentrations of TSH and thyroid hormones are the result of all the processes that occur during the inflammatory reaction, which vary depending on the type and intensity of infection. Moreover, one of the key factors is the duration of infection, which is reflected in the severity and range of changes in the body functions. It should be remembered that even though changes in TSH concentration are usually not observed during NTIS, TSH transiently rises in the first hours of critical illness and during recovery [18,27].

Finding of TSH increase during mild or moderate upper respiratory tract infection may indirectly differentiate common infections in some children with coronavirus disease-19 (COVID-19), referring to the fact, the SARS-CoV-2 virus has a significant affinity to thyroid cells and may cause destructive thyroiditis and transient thyrotoxicosis accompanied by TSH suppression [33].

The limitations of our study, despite its prospective character, are differences in the time-lag between the infection onset and the exact moment when the patient first visited the GP and the patient's blood was drawn. Moreover, we did not determine the patients' hydration status with the application of the blood urea nitrogen/creatinine ratio assessment.

Our observation of the decreasing TSH concentrations after infection in nearly $2 / 3$ of the children suggests that the secretion of this hormone during infection may result from simultaneous processes of stimulation (an increase in TSH concentration, typical of the first hours/days of infection, fasting, fever), as well as inhibition (D2 stimulation in the hypothalamus) of TSH secretion. The latter process occurs in parallel with the inhibition of the peripheral conversion of $\mathrm{T} 4$ to $\mathrm{T} 3$ [34].

Taking into account our results presented above, one should always remember that a diagnosis of thyroid dysfunctions made on the basis of a single TSH measurement only, though perhaps inexpensive and convenient, seems oversimplified and involves a considerable risk of obtaining falsely positive results. Our study demonstrated that acute infection is a condition that may lead to transient elevation of TSH, regardless of the level of inflammatory markers. Thus, the TSH level elevated in a child during or directly after an acute infection should be always re-assessed after the recovery.

\section{Conclusions}

1. Transient hyperthyrotropinemia was observed in about $10 \%$ of children suffering from an acute respiratory tract infection, regardless of its course, location and severity. The etiology for this finding is unclear.

2. If the test is performed during the infection and slightly elevated TSH concentration is noted, the TSH test should be repeated after recovery. Such an approach will allow many patients to avoid expensive diagnostic procedures and unnecessary implementation of treatment.

Author Contributions: Conceptualization, K.A. and R.S.; methodology, R.S. and K.A.; resources, K.A.; writing-original draft preparation, K.A. and Z.A.; writing-review and editing, A.L. and M.S.; supervision, A.L. and R.S. All authors have read and agreed to the published version of the manuscript. 
Funding: This research was funded by statutory funds from the Medical University of Lodz, Lodz, Poland (503/1-107-03/503-11-001-19).

Institutional Review Board Statement: The study was accepted by the Polish Mother's Memorial Hospital-Research Institute Bioethical Committee, approval code 63/2018.

Informed Consent Statement: Informed consent was obtained from all subjects involved in the study.

Data Availability Statement: The data presented in this study are available on request from the corresponding author.

Conflicts of Interest: The authors declare no conflict of interest.

\section{References}

1. Hanley, P.; Lord, K.; Bauer, A.J. Thyroid disorders in children and adolescents: A review. JAMA Pediatr. 2016, 170, 1008-1019. [CrossRef]

2. Leung, A.K.C.; Leung, A.A.C. Evaluation and management of the child with hypothyroidism. World J. Pediatr. 2019, 15, 124-134. [CrossRef] [PubMed]

3. Zygmunt, A.; Adamczewski, Z.; Wojciechowska-Durczynska, K.; Krawczyk-Rusiecka, K.; Bieniek, E.; Stasiak, M.; Zygmunt, A.; Purgat, K.; Zakrzewski, R.; Brzezinski, J.; et al. Evaluation of the effectiveness of iodine prophylaxis in Poland based on over 20 years of observations of iodine supply in school-aged children in the central region of the country. Arch. Med. Sci. 2019, 15, 1468-1474. [CrossRef] [PubMed]

4. Borowiec, A.; Labochka, D.; Milczarek, M.; Kopiec-Burdecka, M.; Artemniak-Wojtowicz, D.; Pyrżak, B.; Kucharska, A.M. Graves' disease in children in the two decades following implementation of an iodine prophylaxis programme. Cent. Eur. J. Immunol. 2018, 43, 399-404. [CrossRef] [PubMed]

5. Gharib, H.; Tuttle, R.M.; Baskin, H.J.; Fish, L.H.; Singer, P.A.; McDermott, M.T.; American Association of Clinical Endocrinologists; American Thyroid Association; Endocrine Society. Consensus Statement \#1: Subclinical thyroid dysfunction: A joint statement on management from the American Association of Clinical Endocrinologists, the American Thyroid Association, and The Endocrine Society. Thyroid 2005, 15, 24-28; response 32-33. [CrossRef] [PubMed]

6. Lazarus, J.; Brown, R.S.; Daumerie, C.; Hubalewska-Dydejczyk, A.; Negro, R.; Vaidya, B. 2014 European thyroid association guidelines for the management of subclinical hypothyroidism in pregnancy and in children. Eur. Thyroid J. 2014, 3, 76-94. [CrossRef] [PubMed]

7. Garber, J.R.; Cobin, R.H.; Gharib, H.; Hennessey, J.V.; Klein, I.; Mechanick, J.I.; Pessah-Pollack, R.; Singer, P.A.; Woeber, K.A.; American Association of Clinical Endocrinologists and American Thyroid Association Taskforce on Hypothyroidism in Adults. Clinical practice guidelines for hypothyroidism in adults: Cosponsored by the American Association of Clinical Endocrinologists and the American Thyroid Association. Endocr. Pract. 2012, 18, 988-1028. [CrossRef] [PubMed]

8. Biondi, B.; Cappola, A.R.; Cooper, D.S. Subclinical hypothyroidism: A review. JAMA 2019, 322, 153-160. [CrossRef]

9. Baloch, Z.; Carayon, P.; Conte-Devolx, B.; Demers, L.M.; Feldt-Rasmussen, U.; Henry, J.F.; LiVosli, V.A.; Niccoli-Sire, P.; John, R.; Ruf, J.; et al. Laboratory medicine practice guidelines. Laboratory support for the diagnosis and monitoring of thyroid disease. Thyroid 2003, 13, 3-126. [CrossRef]

10. Hoermann, R.; Midgley, J.E.; Larisch, R.; Dietrich, J.W. Homeostatic control of the thyroid-pituitary axis: Perspectives for diagnosis and treatment. Front. Endocrinol. 2015, 6, 177. [CrossRef]

11. Kapelari, K.; Kirchlechner, C.; Högler, W.; Schweitzer, K.; Virgolini, I.; Moncayo, R. Pediatric reference intervals for thyroid hormone levels from birth to adulthood: A retrospective study. BMC Endocr. Disord. 2008, 8, 15. [CrossRef]

12. Habib, A.; Molayemat, M.; Habib, A. Elevated serum TSH concentrations are associated with higher BMI Z-scores in southern Iranian children and adolescents. Thyroid Res. 2020, 13, 9. [CrossRef]

13. Van den Berghe, G.; de Zegher, F.; Bouillon, R. Acute and prolonged critical illness as different neuroendocrine paradigms. J. Clin. Endocrinol. Metab. 1998, 83, 1827-1834. [CrossRef]

14. Wehmann, R.E.; Gregerman, R.I.; Burns, W.H.; Saral, R.; Santos, G.W. Suppression of thyrotropin in the low-thyroxine state of severe nonthyroidal illness. N. Engl. J. Med. 1985, 312, 546-552. [CrossRef]

15. Preiser, J.C.; Ichai, C.; Orban, J.C.; Groeneveld, A.B. Metabolic response to the stress of critical illness. Br. J. Anaesth. 2014, 113, 945-954. [CrossRef]

16. Langouche, L.; Jacobs, A.; Van den Berghe, G. Nonthyroidal illness syndrome across the ages. J. Endocr. Soc. 2019, 3, $2313-2325$. [CrossRef]

17. Jacobs, A.; Derese, I.; Vander Perre, S.; van Puffelen, E.; Verstraete, S.; Pauwels, L.; Verbruggen, S.; Wouters, P.; Langouche, L.; Garcia Guerra, G.; et al. Non-Thyroidal Illness Syndrome in Critically Ill Children: Prognostic Value and Impact of Nutritional Management. Thyroid 2019, 29, 480-492. [CrossRef]

18. Hamblin, P.S.; Dyer, S.A.; Mohr, V.S.; Le Grand, B.A.; Lim, C.F.; Tuxen, D.V.; Topliss, D.J.; Stockigt, J.R. Relationship between thyrotropin and thyroxine changes during recovery from severe hypothyroxinemia of critical illness. J. Clin. Endocrinol. Metab. 1986, 62, 717-722. [CrossRef] 
19. C-Reactive Protein Concentrations as a Marker of Inflammation or Infection for Interpreting Biomarkers of Micronutrient Status; Vitamin and Mineral Nutrition Information System, WHO/NMH/NHD/EPG/14.7; World Health Organization: Geneva, Switzerland, 2014.

20. Raberg, L.; Sim, D.; Read, A.F. Disentangling genetic variation for resistance and tolerance to infectious diseases in animals. Science 2007, 318, 812-814. [CrossRef]

21. Schneider, D.S.; Ayres, J.S. Two ways to survive infection: What resistance and tolerance can teach us about treating infectious diseases. Nat. Rev. Immunol. 2008, 8, 889-895. [CrossRef]

22. McEwen, B.S.; Wingfield, J.C. The concept of allostasis in biology and biomedicine. Horm. Behav. 2003, 43, 2-15. [CrossRef]

23. Chatzitomaris, A.; Hoermann, R.; Midgley, J.E.; Hering, S.; Urban, A.; Dietrich, B.; Abood, A.; Klein, H.H.; Dietrich, J.W. Thyroid allostasis-adaptive responses of thyrotropic feedback control to conditions of strain, stress, and developmental programming. Front. Endocrinol. (Lausanne) 2017, 8, 163. [CrossRef] [PubMed]

24. Markanday, A. Acute phase reactants in infections: Evidence-based review and a guide for clinicians. Open Forum Infect. Dis. 2015, 3, 2. [CrossRef] [PubMed]

25. Sanders, S.; Barnett, A.; Correa-Velez, I.; Coulthard, M.; Doust, J. Systematic review of the diagnostic accuracy of C-reactive protein to detect bacterial infection in nonhospitalized infants and children with fever. J. Pediatr. 2008, 153, 570-574. [CrossRef] [PubMed]

26. Maturlo, S.J.; Rosenbaum, R.L.; Pan, C.; Surks, M.I. Variable thyrotropin response to thyrotropin-releasing hormone after small decreases in plasma free thyroid hormone concentrations in patients with nonthyroidal diseases. J. Clin. Investig. 1980, 66, 451-456. [CrossRef] [PubMed]

27. Michalaki, M.; Vagenakis, A.G.; Makri, M.; Kalfarentzos, F.; Kyriazopoulou, V. Dissociation of the early decline in serum T(3) concentration and serum IL-6 rise and TNF alpha in nonthyroidal illness syndrome induced by abdominal surgery. J. Clin. Endocrinol. Metab. 2001, 86, 4198-4205. [CrossRef] [PubMed]

28. Sawhney, R.C.; Malhotra, A.S.; Nair, C.S.; Bajaj, A.C.; Rajan, K.C.; Pal, K.; Prasad, R.; Basu, M. Thyroid function during a prolonged stay in Antarctica. Eur. J. Appl. Physiol. Occup. Physiol. 1995, 72, 127-133. [CrossRef]

29. Oka, K.; Hanayama, Y.; Sato, A.; Omura, D.; Yasuda, M.; Hasegawa, K.; Obika, M.; Otsuka, F. Clinical characteristics of febrile outpatients: Possible involvement of thyroid dysfunction in febrile tachycardia. Acta Med. Okayama 2018, 72, 447-456. [CrossRef]

30. Mustafa, S.; Al-Bader, M.D.; Elgazzar, A.H.; Alshammeri, J.; Gopinath, S.; Essam, H. Effect of hyperthermia on the function of thyroid gland. Eur. J. Appl. Physiol. 2008, 103, 285-288. [CrossRef]

31. Barington, M.; Brorson, M.M.; Hofman-Bang, J.; Rasmussen, Å.K.; Holst, B.; Feldt-Rasmussen, U. Ghrelin-mediated inhibition of the TSH-stimulated function of differentiated human thyrocytes ex vivo. PLoS ONE 2017, 12, 9. [CrossRef]

32. Adamczewska, K.; Adamczewski, Z.; Łupińska, A.; Lewiński, A.; Stawerska, R. Strong positive correlation between TSH and ghrelin in euthyroid non-growth hormone-deficient children with short stature. Molecules 2020, 25, 3912. [CrossRef]

33. Lania, A.; Sandri, M.T.; Cellini, M.; Mirani, M.; Lavezzi, E.; Mazziotti, G. Thyrotoxicosis in patients with COVID-19: The THYRCOV study. Eur. J. Endocrinol. 2020, 183, 381-387. [CrossRef]

34. Fekete, C.; Gereben, B.; Doleschall, M.; Harney, J.W.; Dora, J.M.; Bianco, A.C.; Sarkar, S.; Liposits, Z.; Rand, W.; Emerson, C.; et al. Lipopolysaccharide induces type 2 iodothyronine deiodinase in the mediobasal hypothalamus: Implications for the nonthyroidal illness syndrome. Endocrinology 2004, 145, 1649-1655. [CrossRef] 